\title{
Sex and strain differences in leverpress shock escape behavior
}

\author{
HANK DAVIS, JOHN W. PORTER, JO-ANN BURTON, and SEYMOUR LEVINE \\ University of Guelph, Ontario, Canada \\ and \\ Stanford University School of Medicine, Stanford, California 94305
}

\begin{abstract}
In Experiment I, the performance of male and female Wistar albino and Long Evans hooded rats was compared on a leverpress shock escape procedure. Consistent superiority of Long-Evans over Wistar subjects emerged in measures of escape latency and percentage of session time spent in contact with the lever. Lower escape latencies recorded for females confirmed previous reports of better performance by female compared to male subjects in aversive conditioning procedures. The data suggest the overall advantage of using female Long Evans subjects, despite the fact that this group seldom appear as subjects in the aversive control literature. Experiment II replicated the sex differences in escape latency of normal subjects, but produced a striking reversal in the behavior of castrated animals. The escape latencies of castrated males and females differed significantly from those of their normal counterparts, and castrated males escaped shock more rapidly than castrated females. Results are discussed in terms of gonadal influences on pituitary-adrenal activity, which may underlie the form of escape response required in the present procedure.
\end{abstract}

There is a considerable body of evidence relating sex and strain differences in rats to performance in aversively based learning situations. The majority of this work deals with behavior resulting from a variety of avoidance conditioning procedures. For example, females have shown superior performance in a shuttlebox (Gray, 1971), wheel-turning apparatus (Nakamura \& Anderson, 1962), and leverpress Sidman (free operant) avoidance situation (Barrett \& Ray, 1970). In addition, superior avoidance performance by various strains of albino rats has been reported in comparisons with wild black rats (Powell, 1973), wild cotton rats (Powell \& Morris, 1968), and Norway rats (Boice, 1970). In another study, albinos did not fare as well as domesticated Long-Evans hooded rats, which were shown to be superior to albinos in a wheel-turning avoidance situation (Nakamura \& Anderson, 1962).

There is increasing evidence to suggest that relationships between sex and strain variables and avoidance behavior may not generalize to escape conditioning situations. For example, Wilcock (1968) has surveyed several reports in which little correlation was found between successful escape and avoidance performance (Broadhurst \& Levine, 1963; Deniston, 1959; Wilcock \& Broadhurst, 1967). Thus, despite the fact that escape conditioning represents perhaps the simplest form of aversive

This research was supported in part by Research Grant NICH\&HD 02881 from the National Institutes of Health, and USPHS Award K5-MH-19936 to Seymour Levine. The authors thank Thom Herrmann for his critical comments on the manuscript. Reprints may be obtained from Hank Davis, Department of Psychology, University of Guelph, Ontario, Canada. control, the effects of sex and strain factors may not be known. In a recent paper (Davis \& Burton, 1974), we noted that a casual survey of 20 escape experiments did not reveal a single instance in which albino rats had not been used. Our survey also suggested a similar bias in favor of the use of male subjects. We concluded by stressing the need to explore the basis for such persistent "folklore." This need is underscored by the fact that there does not appear to be a single investigation of the effects of sex and strain of rat subjects on escape behavior involving a leverpress response.

\section{EXPERIMENT I}

The purpose of the following study is to compare performance of male and female rats of the Wistar albino and Long-Evans hooded strains under a conventional leverpress shock escape procedure. In addition to traditional measurement of escape latency, a continuous record of the force of all lever contact will be obtained as such data have been shown to be sensitive to unlearned or reflexive behaviors which may underlie the reinforced escape response (Bolles \& McGillis, 1968; Davis \& Burton, 1974).

\section{Subjects}

\section{Method}

Sixteen Wistar albino rats and 16 Long-Evans hooded rats served as subjects. For each strain, half of the subjects were male and half were female. Prior to the first experimental session, the male subjects were approximately 120 days old and had a mean weight of $394 \mathrm{~g}$. The female subjects were approximately 140 days old and weighed an average of $27.4 \mathrm{~g}$. All of the 
subjects were experimentally naive and were housed individually with ad-lib food and water in their home cages.

\begin{abstract}
Apparatus
The subjects were tested in a Lehigh Valley grid shock chamber with internal dimensions of 12 in. $(30.5 \mathrm{~cm})$ long $\times 8$ in. $(20.3 \mathrm{~cm})$ wide $\times 7.5 \mathrm{in}$. high $(19.0 \mathrm{~cm})$. The floor consisted of 22 stainless steel grids, $3 / 16$ in. $(0.64 \mathrm{~cm})$ in diameter and spaced $1 / 2$ in. $(1.3 \mathrm{~cm})$ center to center. A constant current shock generator and shock scrambler (Campden Instrument Co.) was calibrated to deliver a 0.4-mA shock to the grid floor, cage walls, and response lever. The lever was $1 / 2$ in. $(1.3 \mathrm{~cm}) \times 2$ in. $(5.1 \mathrm{~cm})$ and protruded $7 / 8$ in. $(2.2 \mathrm{~cm})$ from the front cage wall, 2 in. $(5.1 \mathrm{~cm})$ above the grid floor.

To complement traditional measures of escape behavior (e.g., escape latency, response frequency and total duration of lever contact), the amount of downward force the subject exerted on the lever was routed through a transducer circuit (described in detail in Davis \& Burton, 1974) and expressed as a pen deflection on a Beckman Dynograph (Type RS). A Schmitt trigger was calibrated to require a minimum downward exertion of $15 \mathrm{~g}$ in order to terminate shock and operate relay programming and recording circuits. A continuous record of all lever contact, regardless of force, was made for all subjects.
\end{abstract}

\section{Procedure}

Training. Prior to the first experimental session, subjects received a training session in which a $0.4-\mathrm{mA}$ shock was programmed to occur every $30 \mathrm{sec}$ from of fset to onset. A single depression of the lever of at least $15-\mathrm{g}$ force was required to terminate shock. A training criterion of 10 consecutive low-latency ( $2 \mathrm{sec}$ or less) leverpress escape responses was achieved by all subjects.

Testing. During testing, the subjects were exposed to 12 daily sessions with 50 shock presentations per session. The intertrial interval (ITI) was $30 \mathrm{sec}$ and shock intensity remained at $0.4 \mathrm{~mA}$. Lever contact in the absence of shock was recorded, but had no programmed consequence.

\section{Results}

All subjects learned to escape shock with mean latencies of less than $1 / 2 \mathrm{sec}$, although significant differences emerged for both strain and sex. LongEvans subjects terminated shock more rapidly than Wistar subjects $(F=8.56, \mathrm{df}=3,28, \mathrm{p}=.007)$, and the mean escape latency of females was shorter than that recorded for males $(F=4.14, \mathrm{df}=3,28$, $\mathrm{p}=.05)$ (see Table 1$)$.

Measurement of the amount of session time subjects spent in contact with the lever, irrespective of the force exerted, revealed that Long-Evans subjects spent significantly more time in contact with the lever than Wistar subjects $(F=11.16$, df $=3,28$, $\mathrm{p}=.003$ ) (see Table 1). The general characteristics of lever holding were comparable for all subjects, regardless of sex or strain. The force of lever contact remained essentially stable throughout the intertrial interval and showed no systematic increase or decrease in force exceeding $15 \mathrm{~g}$ across the intertrial interval (see Figure 1).

All subjects, however, did show a systematic decline in the mean force of lever contact exerted over sessions. An analysis of mean response force over blocks of three sessions revealed decreases between first and fourth session blocks ranging between $24 \%$ and $36 \%$, with a $28 \%$ average decline for all subjects.

During the initial session block, considerable group differences were recorded in the mean force of lever contact. Males responded with significantly greater force than females $(F=7.74$, $\mathrm{df}=3,28, \mathrm{p}=.009)$, and Long-Evans subjects exerted somewhat more force than Wistars, although this difference did not reach significance $(F=2.57, \mathrm{df}=3,28, \mathrm{p}=.116)$ (see Table 1). An analysis of covariance revealed that neither strain nor sex differences in force recorded during the initial block of escape sessions were attributable to weight differences between subjects.

During the final block of three sessions, LongEvans subjects exerted significantly more force in contact with the lever than Wistar subjects $(F=5.45$, df $=3,28, p=.025)$, although an analysis of covariance revealed a considerable relationship between these data and strain differences in weight $(\mathrm{F}=3.89, \mathrm{df}=3,28, \mathrm{p}=.056)$. Male subjects exerted somewhat greater force on the lever than females $(F=2.68$, df $=3,28, p=.109)$, although this difference failed to reach significance. An analysis of covariance did not reveal a significant relationship between response force and weight differences for males and females during this period.

\section{Discussion}

The present experiment has compared male and

Table 1

Differences in Measures of Escape Performance for Male and Female Long-Evans Hooded and Wistar Albino Rats

\begin{tabular}{|c|c|c|c|c|c|}
\hline & \multicolumn{2}{|c|}{ Long-Evans } & \multicolumn{2}{|c|}{ Wistar } & \\
\hline & Males & Females & Males & Females & \\
\hline$\overline{\mathrm{X}}$ escape latency & $.36 \mathrm{sec}$ & $.26 \mathrm{sec}$ & $.40 \mathrm{sec}$ & $.38 \mathrm{sec}$ & $\begin{array}{l}\text { LE }>W, p=.007 \\
f>m, p=.05\end{array}$ \\
\hline$\%$ session on lever & $88 \%$ & $93 \%$ & $73 \%$ & $61 \%$ & $\mathrm{LE}>\mathrm{W}, \mathrm{p}=.003$ \\
\hline$\overline{\mathrm{X}}$ force/initial session block & $61 \mathrm{~g}$ & $45 \mathrm{~g}$ & $50 \mathrm{~g}$ & $42 \mathrm{~g}$ & $\begin{array}{l}m>f, p=.009 \\
L E>W, p=.116\end{array}$ \\
\hline$\overline{\mathrm{X}}$ force/final session block & $45 \mathrm{~g}$ & $34 \mathrm{~g}$ & $32 \mathrm{~g}$ & $31 \mathrm{~g}$ & $\begin{array}{l}\mathrm{LE}>\mathrm{W}, \mathrm{p}=.025 \\
\mathrm{~m}>\mathrm{f}, \mathrm{p}=.109\end{array}$ \\
\hline
\end{tabular}




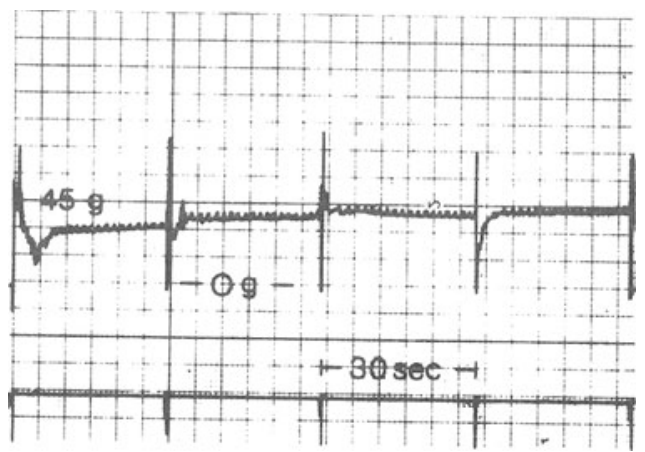

Figure 1. Illustrative record of lever contact during four consecutive shock escape trials. Each heavy ruling along vertical axis represents a $15-\mathrm{g}$ increment in force of lever contact. Heavy rulings along the horizontal axis represent 5 -sec periods. Shock occurrences are indicated by blips on the lower record. The "response" which terminates shock typically results from the subject's remaining in contact with the lever throughout the shock-free intertrial interval and making a "reflexive lurch" from the lever (shown on record as brief spike of peak magnitude force) when shock occurred.

female Wistar albino and Long-Evans hooded rats in a leverpress shock escape procedure. Both sex and strain differences were recorded on a variety of behavioral measures, including mean escape latency, percentage of session time spent in contact with the lever, and mean force of lever contact.

There are a number of similarities between the present results and sex differences reported in the avoidance conditioning literature. For instance, the superiority of female rats under the present escape procedure is consistent with virtually every comparison made between male and female rats in avoidance situations (Barrett \& Ray, 1970; Gray, 1971; Nakamura \& Anderson, 1962). Such findings may relate to some general underlying variable such as "emotionality" or "fearfulness." The notion of such a general sex-related state has ample precedent in the literature (Broadhurst, 1957; Gray, 1971) and appears necessary in light of the broad array of procedures under which female superiority has been demonstrated.

Despite a considerable literature on strain differences, there is little evidence of a consistent pattern of behavioral effects for any particular comparison of strains. The present study appears to be the only comparison of Long-Evans hooded and Wistar albino subjects in an aversively based learning situation. The most closely related evidence comes from a study by Nakamura and Anderson (1962), which reports superior avoidance performance by LongEvans rats in a comparison with Sprague-Dawley albinos. The relevance of this finding is somewhat questionable, however, since Sprague-Dawley and Wistar albinos have been shown to be significantly different in yet another comparison of avoidance performance (Myers, 1959).
It seems unlikely that strain comparisons would reveal as consistent a pattern of behavioral results across different aversive control procedures as that reported for sex comparisons. For one thing, the sex of a subject is considerably easier to specify than its strain. A number of investigators have begun to note substantial behavioral differences within a strain, often resulting from different breeding practices employed by suppliers purporting to sell identical strains (Hurwitz \& Dillow, 1966; Nakamura \& Anderson, 1962).

Another factor mitigating against consistent strain effects is the variety of behavioral requirements imposed by different aversive control procedures. In contrast to sex differences which may be related to a "general state," strain differences have been described in more behavior-specific terms (Barrett, Leith, \& Ray, 1973; Bolles, 1970). The relative availability of a particular behavior (e.g., fleeing, freezing), which may vary between strains, would thus directly affect how successful that strain was in a given learning situation. For example, a particular strain might show great success on one avoidance task (e.g., alley running) and minimal efficiency in another (e.g., leverpressing), despite comparable motivation. Given that both avoidance and escape procedures vary considerably in the specific response which is reinforced (Brener \& Goesling, 1970; Keehn, 1967), it is not unreasonable to expect considerable strain differences across different experimental procedures, despite the fact that they may be broadly classified as "avoidance" or "escape."

It is notable that of the four groups of rats tested in the present study, female Long-Evans appear to be used least commonly in aversive control research. In fact, there does not appear to be a single leverpress escape experiment in which female Long-Evans rats served as subjects. Whether this bias is based on a general preference for albinos ("more docile") or on a bias against female rats (too "skittish" or behaviorally variable during oestus) is unclear. Nevertheless, it is ironic that these unpopular subjects were most successful in the present experiment. Their escape latencies were substantially lower and showed less within-subject variability than those of any other group. Moreover, Long-Evans female subjects remained in contact with the lever more than any other group (an average of $93 \%$ of the session), an essential concommitant of leverpress escape (Bolles \& McGillis, 1968; Campbell, 1962).

\section{EXPERIMENT II}

Consistent with a substantial body of experimental work in aversively based learning situations, the previous experiment has demonstrated the superiority of female rats in a leverpress shock escape proce- 
Table 2

Differences in Measures of Escape Performance for Normal and Castrated Male and Female Rats

\begin{tabular}{|c|c|c|c|c|c|}
\hline & \multicolumn{2}{|c|}{ Normal } & \multicolumn{2}{|c|}{ Castrated } & \\
\hline & Males & Females & Males & Females & \\
\hline $\bar{X}$ Escape Latency & $.31 \mathrm{sec}$ & $.22 \mathrm{sec}$ & $.21 \mathrm{sec}$ & $.39 \mathrm{sec}$ & $\begin{array}{ll}\text { NF }>\text { NM } & p<.05 \\
\text { CM }>\text { CF } & p<.001 \\
\text { CM }>\text { NM } & p<.05 \\
\text { NF }>\text { CF } & p<.01\end{array}$ \\
\hline$\%$ session on lever & $77 \%$ & $69 \%$ & $73 \%$ & $83 \%$ & $\begin{array}{ll}\mathrm{CF}>\mathrm{NF} & \mathrm{p}<.01 \\
\mathrm{CF}>\mathrm{CM} & \mathrm{p}<.05 \\
\mathrm{NM}>\mathrm{NF} & .10>\mathrm{p}>.05\end{array}$ \\
\hline$\overline{\mathrm{X}}$ force/initial session block & $55 \mathrm{~g}$ & $39 \mathrm{~g}$ & $51 \mathrm{~g}$ & $41 \mathrm{~g}$ & \\
\hline$\overline{\mathrm{X}}$ force/final session block & $41 \mathrm{~g}$ & $27 \mathrm{~g}$ & $33 \mathrm{~g}$ & $33 \mathrm{~g}$ & \\
\hline
\end{tabular}

dure. In order to determine to what extent the present findings are influenced by the continued production of sexual hormones and activation of the pituitarygonadal system, adult male and female subjects in Experiment II were first castrated and then exposed to the shock escape procedure.

\section{Subjects \\ Method \\ Sixteen Long-Evans hooded rats, eight male and eight female, served as subjects. All subjects were approximately 140 days old prior to the first experimental session. The subjects were randomly assigned to one of four experimental groups: normal male (NM), normal female (NF), castrated male (CM), and castrated female (CF). All subjects were housed individually with food and water freely available in their home cages.}

\section{Surgery}

At approximately 125 days of age, subjects in Groups CM and CF were castrated by surgical removal of the testes or ovaries. Following surgery, all subjects were allowed 15 days to recover from the surgical procedure.

\section{Apparatus \\ Subjects were tested in one of two identical Lehigh Valley grid shock chambers described in Experiment I. The force of all lever contact was continuously monitored using the apparatus described in Experiment I. \\ Procedure \\ Methods of training and testing were identical to those employed in Experiment I.}

\section{Results}

An analysis of variance yielded significant results for both escape latency $(F=7.7, \mathrm{df}=3,12, \mathrm{p}<.01)$ and amount of lever contact $(F=3.5$, df $=3,12$, $\mathrm{p}=.05$ ). Table 2 summarizes the major results of Experiment II derived from individual comparisons using Duncan's multiple range test.

The basic finding that female rats escape shock more rapidly than males was replicated with normal subjects in Experiment II $(\mathrm{p}<.05)$. This difference between male and female subjects was reversed by castration, however, as castrated males escaped shock more rapidly than castrated females $(p<.001)$. In addition, castrated and normal males had significantly different escape latencies $(p<.05)$, as did castrated and normal females $(p<.01)$. The escape latencies of normal males and castrated females were not significantly different; neither were those of normal females and castrated males.

The effects of castration on amount of lever contact appeared to be greater for females than for males, as normal and castrated males did not differ, whereas castrated females spent significantly more time on the lever than normal females $(p<.01)$. There was some tendency for normal males to spend more session time in contact with the lever than normal females, although this difference was only marginally significant $(.10>p>.05)$ and was reversed by castration (see Table 2).

As observed in Experiment I, all subjects showed a consistent decrease in the mean force of lever contact exerted across experimental sessions. Declines recorded between the first and final blocks of three sessions ranged between $20 \%$ and $35 \%$ and averaged $27.5 \%$ for all subjects. An analysis of covariance revealed no relationship between a subject's weight and the force it exerted on the lever.

\section{Discussion}

The present experiments indicate that superior performance by female subjects (vs. male) on a shock escape procedure can be reversed by gonadectomy. Thus, the escape performance of the castrated male closely resembles that of the intact female, and performance of the castrated female does not differ from that of the intact male.

These results are not consistent with previous reports that castration during adulthood typically fails to alter sex differences in behavior maintained by an aversive control procedure (e.g., Beatty \& Beatty, 1970). It should be noted, however, that, unlike previous research, the present escape procedure involves a leverpress response. This is an important distinction, as it has been repeatedly argued that both the behavioral and physiological results of an aversive control procedure may be specific to the response requirement employed, rather than to the label "escape" or "avoidance" per se (DiGuisto, Cairncross, \& King, 1971). In the present case, a 
comparison of escape latencies with those typically produced in the shuttlebox, for example, suggests that fundamentally different behaviors may be under investigation, despite the common use of "escape" or "avoidance" to label them. That differences in the magnitude of leverpress escape latencies are quite small, although statistically significant, is not surprising in view of the fact that it has been demonstrated that this response may be largely reflexive in nature (Bolles \& McGillis, 1968; Davis \& Burton, 1974).

The question remains as to what effect changes in gonadal hormones have on an essentially reflexive shock escape response. Because there is little evidence that the gonadal hormones have any direct effect upon escape and avoidance behavior, it is more likely that the present effects of gonadectomy are due to the influence of gonadal hormones on the pituitary-adrenal system. The pituitary-adrenal axis may, in turn, be tied directly to both reflexive and escape behavior. For example, the relevance of the pituitary-adrenal system to reflexive behavior was investigated in a study by Johnson (1970), who reports that suppression of ACTH by an implant of hydrocortisone directly into the median eminence suppressed a reflexive response to an auditory stimulus.

There are numerous reports which clearly indicate the existence of sex differences in pituitary-adrenal activity. Moreover, these sex differences and the effects of castration upon them are parallel in direction to the sex differences in escape performance reported in the present paper. For example, the normal female typically exhibits a higher level of pituitaryadrenal response than the male, both in the resting state and when exposed to stress (Critchlow, Liebolt, Bar-Sela, Mountcastle, \& Lipscomb, 1964; Dunn, Scheving, \& Millet, 1972; Kitay, 1961). These differences in intact animals seem to occur as a combined effect of estradiol and testosterone on pituitary ACTH, and adrenal synthesis and release of corticosterone. Following gonadectomy, ACTH is typically increased in the male as indicated by adrenal hyperplasia. In contrast, oviarectomy produces adrenal atrophy, suggesting a suppression of ACTH release and synthesis in the female following the removal of the ovaries (Kitay, 1963).

The relationship between pituitary-adrenal activity and leverpress escape behavior has been previously suggested (de Wied, 1964) and was examined directly in a recent experiment (Davis, Porter, Livingstone, $\&$ Levine, Note 1). Pituitary-adrenal activity, monitored through plasma corticosterone levels, was shown to increase significantly during exposure to an escape conditioning procedure. In addition, implants of cortisol in the median eminence region of the hypothalamus, known to inhibit synthesis of ACTH, resulted in deficits in escape behavior. The fact that escape latencies are increased significantly when ACTH is suppressed, combined with the opposite effects of gonadectomy on ACTH in males and females, could account for the changes observed in the present experiment. Thus, higher ACTH levels in the normal female as compared to the intact male could account for the original sex differences in escape latencies. Moreover, increased ACTH in the male following castration is consistent with the decreased latency which occurs following the removal of the gonads. Conversely, the increase in escape latency of the female may be explicable in terms of decreased levels of ACTH following ovariectomy. Thus, it is reasonable to view the present differences in leverpress escape behavior in terms of sexmediated influences of the pituitary-adrenal system on a reflexive shock escape response.

The present experiments have replicated and extended one general finding: the superior performance of female subjects on an aversive control procedure. It is important to stress that virtually every other result in the present study, from superior performance by Long-Evans subjects in Experiment I to the castration-based reversal of male and female performance in Experiment II, is likely related to the leverpress escape response and may not be general to other aversive control procedures. It is hoped that future research of this nature will approach sex, strain, or hormone-related effects as being specific to particular behaviors, rather than relating the effects of these variables to broad classes such as escape, avoidance, and aversive control.

\section{REFERENCE NOTE}

1. Davis, H., Porter, J. W., Livingstone, J., \& Levine, S. The role of pituitary-adrenal activation in leverpress shock escape behavior. Unpublished manuscript, 1976.

\section{REFERENCES}

Barrett, R. S., Leith, N. J., \& RAY, O. S. A behavioral and pharmacological analysis of variables mediating active avoidance behavior in rats. Journal of Comparative and Physiological Psychology, 1973, 83, 189-200.

BARRETT, R. S., \& RAY, O. S. Behavior in the open field, Lashley III maze, shuttlebox, and Sidman avoidance as a function of strain, sex, and age. Developmental Psychology, 1970, 3, 73-77.

Beatty, W. W., \& Beatty, P. A. Hormonal determinants of sex differences in avoidance behavior and reactivity to electric shock in the rat. Journal of Comparative Physiological Psychology, $1970,73,446-455$.

BoICE, R. Effect of domestication on avoidance learning in the Norway rat. Psychonomic Science, 1970, 13, 13-14.

Bolles, R. C. Species-specific defense reactions and avoidance learning. Psychological Review, 1970, 77, 32-48.

Bolles, R. C., \& McGillis, D. B. The non-operant nature of the bar-press escape response. Psychonomic Science, 1968, 11, 261-262.

Brener, J., \& Goesling, W. J. Avoidance conditioning of activity and immobility in rats. Journal of Comparative and Physiological Psychology, 1970, 70, 276-280. 
Broadhurst, P. L. Determinates of emotionality in the rat. I. Situational factors. British Journal of Psychology, 1957, 48, 1-12.

Broadhurst, P. L., \& Levine, S. Behavioral consistency in strains of rats selectively bred for emotional elimination. British Journal of Psychology, 1963, 54, 121-125.

CAMPBElL, S. L. Lever holding and behavior sequences in shock escape. Journal of Comparative and Physiological Psychology, 1962, 55, 1047-1053.

Critchlow, V., Liebelt, R. A., Bar-Sela, M., Mountcastle, W., \& Lipscomb, H. S. Sex difference in resting pituitaryadrenal function in the rat. American Journal of Physiology, 1964, 205, 807-815.

Davis, H., \& Burton, J. The measurement of response force during a lever-press shock-escape procedure in rats. Journal of the Experimental Analysis of Behavior, 1974, 2, 175-182.

DenNiston, R. H. Escape and avoidance learning as a function of emotionality level in the Wyoming squirrel (Cifellus richardsonil elegans). Animal Behaviour, 1959, 7, 241-243.

DE WIED, D. Influence of anterior pituitary on avoidance learning and escape behavior. American Journal of Physiology, 1964, 207, 255-259.

Di Giusto, E., Cairncross, K., \& King, M. Hormonal influences of fear-motivated responses. Psychological Bulletin, 1971, 75. $432-444$.

Dunn, J.. Scheving, L., \& Millet, P. Circadian variation in stress-evoked increases in plasma corticosterone. American Journal of Physiology, 1972, 223, 402-406.

GrAY, J. A. Sex differences in emotional behavior in mammals including man: Endocrine bases. Acta Psychologia, 1971, 35, $39-46$.

HuRwitz, H. M. B., \& Dillow, P. V. The effect of strain of rats on the acquisition of discriminated avoidance response. Psychonomic Science, 1966, 6, 401-402.
Johnson, J. E. T. Influence of pituitary-adrenal hormones on habituation and conditioned avoidance behavior. $\mathrm{PhD}$ dissertation, Stanford University, 1970.

KEEHN, J. D. Running and bar pressing as avoidance responses. Psychological Reports, 1967, 20, 591-602.

KitAy, J. I. Sex differences in adrenal cortical secretion in the rat. Endocrinology, 1961, 68, 818-824.

KiTAY, J. I. Pituitary-adrenal function in the rat after gonadectomy and gonadal hormone replacement. Endocrinology, 1963, 73, 253-260.

Myers, A. K. Avoidance learning as a function of several training conditions and strain differences in rats. Journal of Comparative and Physiological Psychology, 1959, 52, 381-386.

Nakamura, C. Y., \& ANDerson, N. H. Avoidance behavior differences within and between strains of rats. Journal of Comparative and Physiological Psych.slogy, 1962, 55, 740-747.

Powell, R. W. Free operant (Sidman) avoidance in reciprocally cross fostered wild and domesticated rats. Bulletin of the Psychonomic Society, 1973, 1, 41-44.

Powell, R. W., \& Morris, G. A. A comparison of escape and avoidance conditioning in wild and domesticated rats. Journal of the Experimental Analysis of Behavior, 1968, 11, 473-478.

Wilcock, J. Strain differences in response to shock in rats selectively bred for emotional elimination. Animal Behaviour, 1968. 16. 294-297.

Wilcock. J., \& BRoadhuRst. P. L. Strain differences in emotionality: Open field and conditioned avoidance behavior in the rat. Journal of Comparative and Physiological Psychology, 1967, 63, 335-338.

(Received for publication February 3, 1976; accepted March, 17, 1976.) 